\title{
10 Jahre höchste Sicherheit
}

Dentsply Sirona Instruments erfüllt mit dem Kombinations-Autoklaven DAC UNIVERSAL seit 10 Jahren die höchsten Hygieneanforderungen an die Zahnarztpraxis. Die Weiterentwicklung des Geräts durch den Flex-Deckel verbreitert das Anforderungsprofil und schließt die Hygienelücke bei der maschinellen Aufbereitung. Gegenüber anderen Aufbereitungsmethoden bietet das Gerät neben Prozesssicherheit einen großen Zeitvorteil, denn er reinigt, ölt und sterilisiert als einziges Gerät auf dem Markt bis zu 6 Turbinen, Hand- und Winkelstücke in 16 min. Bei der Reinigung kommen keine chemischen Zusätze zum Einsatz, was sich auf die Lebensdauer der Instrumente positiv auswirkt. Zur IDS 2015 erweiterte das Unternehmen den Kombinati-

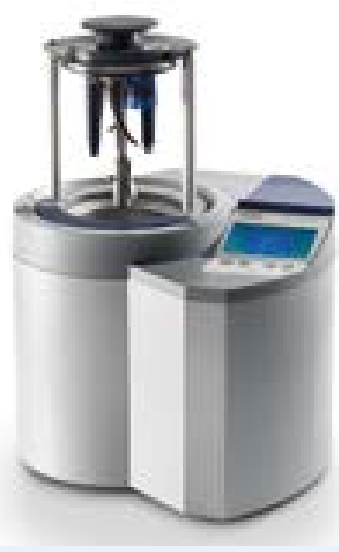
onsautoklaven um die Aufbereitungsmöglichkeit weiterer Instrumente. Durch den neuen Flex-Deckel können nun auch Ultraschallspitzen, -handstücke und Düsen von Multifunktionsspritzen innen und außen gereinigt und thermisch desinfiziert werden. Mit dem Standard-Deckel lassen sich bis zu 6 unverpackte Übertragungsinstrumente reinigen, pflegen und sterilisieren oder mit einem Drahtkorb massive Instrumente wie Sonden, Spiegel oder Küretten aufbereiten. Die Ultraschallspitzen werden gemeinsam mit dem dazugehörigen Drehmomentschlüssel aufbereitet und durchlaufen dabei einen geschlossenen und vollautomatischen Hygienekreislauf, wodurch Fehlerquellen ausgeschlossen werden. Über unterschiedliche Adapter können zudem Instrumente verschiedener Hersteller im DAC UNIVERSAL aufbereitet werden.

Nach einer Pressemitteilung der Dentsply Sirona Instruments, Bensheim www.dentsplysirona.com. 